\title{
Perspective
}

\section{Hemovigilence - Application in Tertiary Care Hospitals}

\author{
Nazish Saqlain* \\ Department of Hematology \& Transfusion Medicine, The Children's Hospital \& Institute of Child Health, Lahore, Pakistan.
}

The therapeutic uses of blood and its components are very well established as a lifesaving tool but at the same time one should not forget about the adverse effects related to it. The desired safe blood transfusions can be done only if there are enough healthy donors in the society making it a precious therapy. In order to cover these aspects, the term Hemovigilance was added to define blood safety. It is a surveillance mechanism covering the entire blood transfusion, donor vein to recipient vein chain, starting from the collection of blood and its components to the follow up of the recipients. WHO defines it as a process of monitoring, reporting, investigation and analysis of adverse or undesirable events related to the transfusion of blood and its components and taking actions to prevent their occurrence or recurrence [1]. The final results play an essential role in ensuring patient safety by learning from failures and then placing corrective changes in the system to prevent such events in future. The awareness can be generated only after knowing the trends of transfusion hazards at a particular set up $[1,2]$.

In 1993, hemovigilance was first started in France where it was mandatory to report while after three years first voluntary reporting system was introduced in United Kingdom. Many countries have their Hemovigilance program linked to International Hemovigilance Network (IHN), which at present has 34 members including Pakistan since February 2013 [2]. The developing countries including ours are still struggling to establish a comprehensive hemovigilance system at a national level. The Asian countries have a fragmented system with scarcity of data related to post transfusion adverse events except for Japan [3]. India started its hemovigilance program in 2012 [4, 5]. In Pakistan the central hemovigilance system plan was proposed by Safe blood Transfusion program in which Hospital Transfusion Committees will be responsible for conveying Hemovigilance related information to provincial Blood Transfusion Authorities who will be connected to Pakistan Hemovigilance Network (PNH). PNH will assemble Annual Reports, which would help to plan future strategy regarding blood transfusion safety [6].

How to make it happen? First of all, any hemovigilance system should take on board all appropriate stakeholders and should be harmonized between the blood transfusion service

\footnotetext{
*Address correspondence to this author at the Department of Hematology \& Transfusion Medicine, The Children's Hospital \& Institute of Child Health, Lahore, Pakistan. E-mail: nazish68@yahoo.com
}

or blood bank, clinical staff and transfusion laboratories, hospital transfusion committees, and national health authorities as per WHO recommendations. The important four levels identified for the implementation of hemovigilance steps include hospitals, blood transfusion services, national authorities and international organizations (Fig. 1) [7].

\section{FOUR LEVELS OF HEMOVIGILANCE APPLICATION}

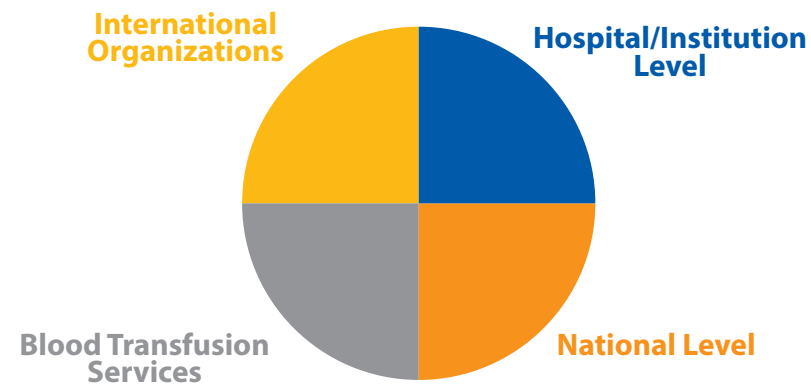

Fig. (1). Four Levels of Hemovigilance Application.

The important steps to be taken at each of these levels in order to establish an effective hemovigilance are summarized in Figs. (2-4).

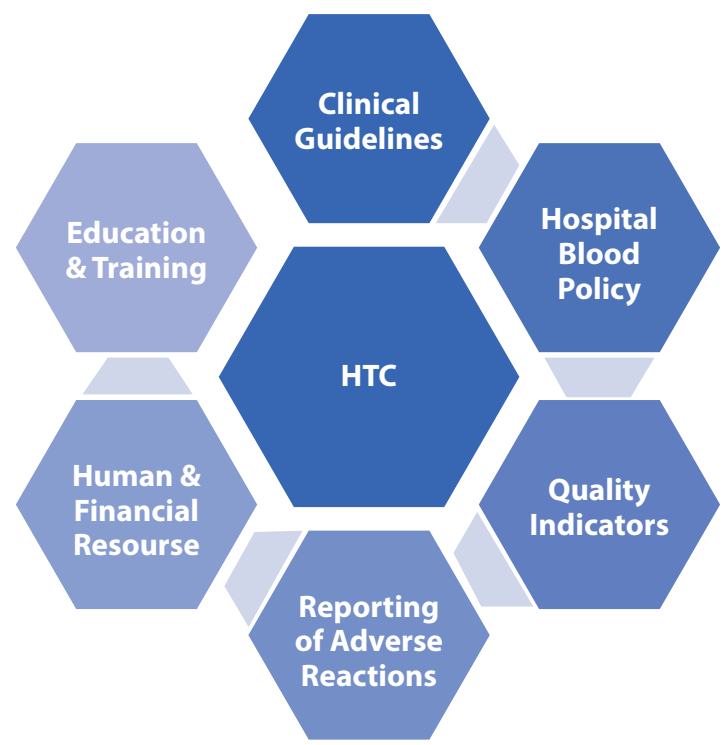

Fig. (2). Steps Required at Hospital/Institution Level. 


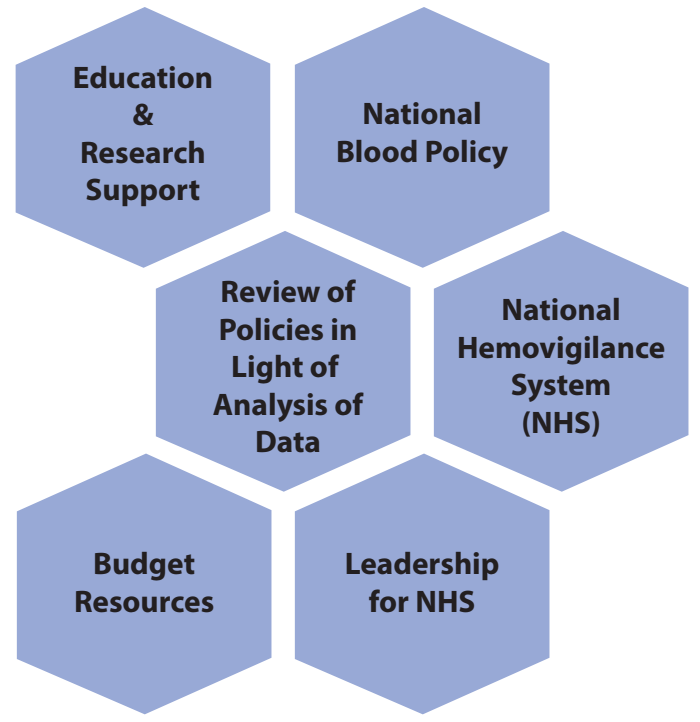

Fig. (3). Steps Required at National Level.

Recommendations proposed by Global Consultation on Hemovigilance held in November 2012 at Dubai, UAE, organized by WHO HQ, Sharjah Blood Transfusion and

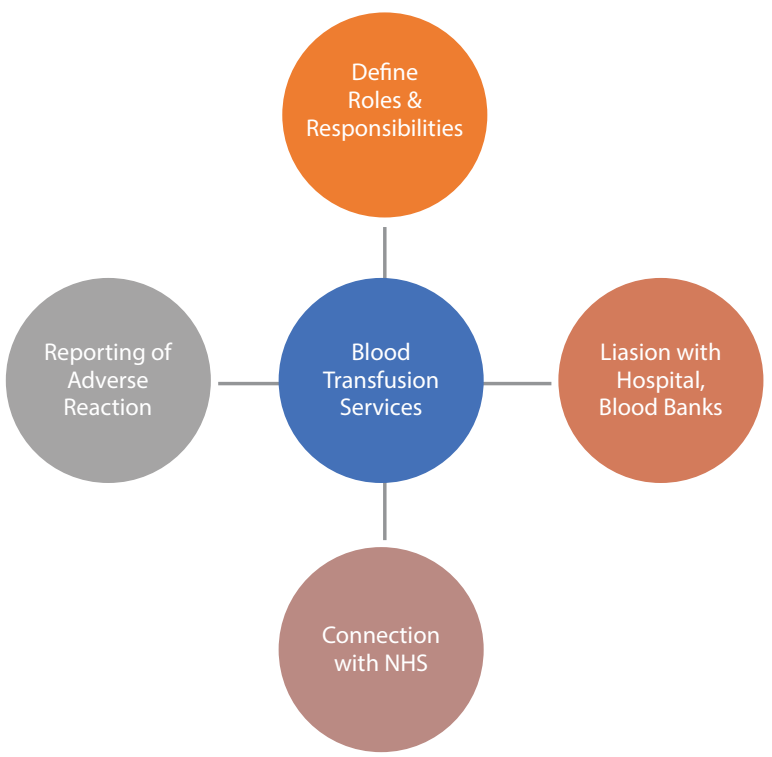

Fig. (4). Steps Required at Blood Transfusion Services Level.

Research Center and the Government of UAE, the International Haemovigilance Network and the ISBT (Fig. 5).

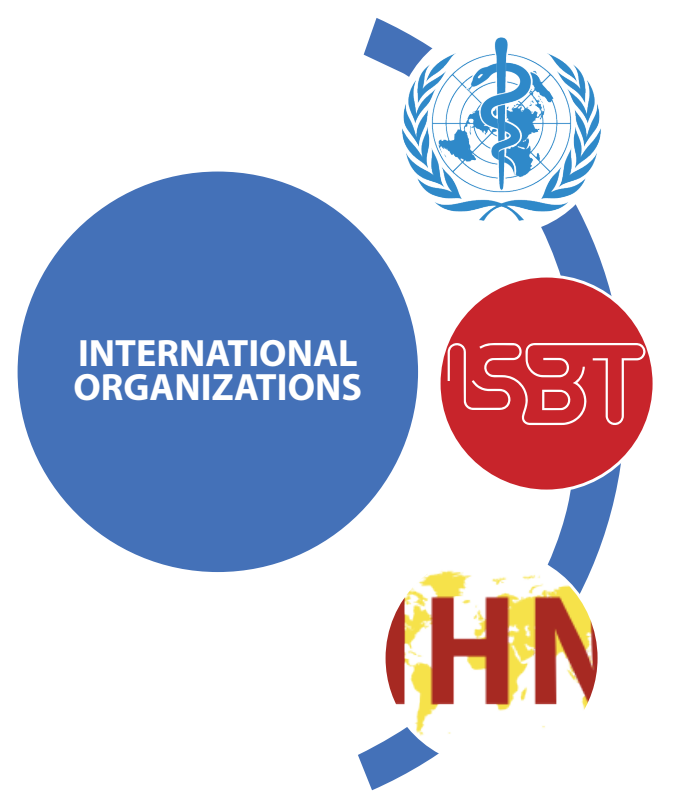

Encouarge national health authorities to establish and improve haemovigilance systems

Global techinal guidelines \& Technical support

Education, Training, Research

Networking support \& establishment of partnerships between members

Fig. (5). International Organizations Working for Hemovigilance.

WHO: World Health Organization, IHN: International Haemovigilance Network, ISBT: International Society of Blood Transfusion.

Hospitals in Pakistan were encouraged to establish hospital transfusion committees and in Punjab province it was declared mandatory by Punjab Health Care Commission. But satisfactory functional status is still not achieved by many. As mentioned in an overview in National Blood Policy and
Strategic framework 2008-2012 document, resource limitation was the major contributing factor in this regard [8]. However, all the hospitals or institutions are required to have clinical blood transfusion guidelines, hospital blood policy and a sound reporting system of transfusion related adverse events. Clinical audits should be carried out at regular intervals regarding different aspects of blood banking. Agnihotri N, et al. conducted a study in a tertiary care hospital in India and concluded that by collecting active feedback on 
all the transfused blood units rather than depending on passive reporting of the blood transfusion reactions greatly improved the reporting so they proposed an active hemovigilance program with a trained and well sensitized staff to collect such data [5].

In Pakistan, we do have a National Blood Policy and Central Hemovigilance system is in its initial phases. Education and training of related staff and public awareness campaigns are essential. Financial support by National authorities has always been the key factor.

The importance of hemovigilance was best exemplified by switching to male donors for most of the FFP production in Switzerland where hemovigilance data revealed that TRALITransfusion Related Acute Lung Injury, was the most common transfusion reaction of immune origin [9]. After this adaptation the incidence of TRALI reduced dramatically. Hemovigilance ensures the safety of a blood transfusion, a true quality indicator. The data needs to be collected according to a standardized form so that it can be properly analyzed to draw inferences. Picture based on reality has to be seen in order to place corrective steps in national blood policy and vigorous effort are required at all the levels for the implementation of hemovigilance related laws and regulations.

\section{CONFLICT OF INTEREST}

Declared none.

\section{ACKNOWLEDGEMENTS}

Declared none.

Received: February 19, 2019

C 2019 National Journal of Health Sciences.

This is an open-access article.

\section{REFERENCES}

[1] de Vries RR, Faber JC, Strengers PF, Board of the International Haemovigilance Network. Haemovigilance: An effective tool for improving transfusion practice. Vox Sang 2011; 100: 60-7. DOI: 10.1111/j.1423-0410.2010.01442.x

[2] https://ihn-org.com/membership/national-internationalhaemovigilance-systems.

[3] Jain A, Kaur R. Hemovigilance and blood safety. Asian J Transfus Sci 2012; 6: 137-8. DOI: 10.4103/0973-6247.98911

[4] Bisht A, Singh S, Marwaha N. Hemovigilance program-India. Asian J Transfus Sci 2013; 7: 73-4. DOI: $10.4103 / 0973-6247.106744$

[5] Agnihotri N, Agnihotri A. Active hemovigilance significantly improves reporting of acute non-infectious adverse reactions to blood transfusion. J Hematol Blood Transfus 2016; 32(3): 335-42. DOI: 10.1007/s12288-015-0568-4

[6] Global Consultation on Haemovigilance. In: WHO Global Consultation on Haemovigilance. Geneva, Switzerland: WHO Press 2012; Available at:https://www.who.int/bloodsafety /haemovigilance/haemovigilance-report.pdf

[7] http://sbtp.gov.pk/collaborations/national-collaborations/ pakistan-haemovigilance-network/

[8] www.sbtp.gov.pk/media/1350/national-blood-policystrategic-framework-2008-12

[9] Jutzi M, Levy G, Taleghani BM. Swiss Haemovigilance Data and Implementation of Measures for the Prevention of Transfusion Associated Acute Lung Injury (TRALI). Transfus Med Hemother 2008; 35: 98-101. DOI: 10.1159/000119120 